\title{
Endoplasmic Reticulum Stress, Inflammation, and Perinatal Brain Damage
}

\author{
WOLFGANG BUETER, OLAF DAMMANN, AND ALAN LEVITON \\ Departments of Obstetrics and Pediatrics [W.B., O.D.], Hannover Medical School, 30623 Hannover, Germany; Department of Pediatrics \\ [O.D.], Tufts-New England Medical Center, Boston, Massachusetts 02111; Department of Neurology [O.D., A.L.], Children's Hospital and \\ Harvard Medical School, Boston, Massachusetts 02215
}

\begin{abstract}
Inflammation seems to play a role in the pathogenesis of perinatal brain damage in fetuses/infants born much before term. We raise the possibility that noninflammatory phenomena induce endoplasmic reticulum stress, which, in turn, leads to the unfolded protein response, which is followed by apoptosis-promoting processes and inflammation. Perhaps by these events, noninflammatory stimuli lead to perinatal brain damage. (Pediatr Res 66: 487-494, 2009)
\end{abstract}

$\mathrm{P}$ erinatal brain white matter damage, especially in the preterm newborn, is likely to have multiple causes (1). White matter cells that play a key role in the pathophysiology of periventricular white matter damage in animal models include preoligodendrocytes (2-4) and microglia/macrophages (5-7). Preoligodendrocytes, the precursors of myelinating oligodendrocytes (OLs), which constitute a major glial population in the white matter, are highly vulnerable to various insults. Antenatal infection and subsequent inflammation comprise one etiologic pathway that links preterm delivery and brain/ lung damage in preterm newborns (8). Some of the damage probably reflects extracellular signaling (with such proteins as cytokines and growth factors) (9), as well as intercellular signaling, (e.g., microglial-oligodendrocyte communication). In this article, we look inside the cell in search of intracellular mechanisms. The central topic of this article is the interrelationships between inflammation and endoplasmic reticulum (ER) stress (Fig. 1). We raise the possibility that ER stress contributes to perinatal brain damage in the infant born much before term.

\section{ENDOPLASMIC RETICULUM STRESS}

The ER is an intracellular organelle consisting of a membranous network that extends throughout the cytoplasm of the cell and is contiguous with the nuclear envelope. In eukaryotic

Received April 1, 2009; accepted July 17, 2009.

Correspondence: Wolfgang Bueter, M.D., Perinatal Neuroepidemiology Unit OE 6415, Departments of Obstetrics and Pediatrics, Hannover Medical School, 30623 Hannover, Germany; e-mail: bueter.wolfgang@mh-hannover.de

Supported by grants from the Wilhelm Hirte Stiftung (Hannover), and the European Union (LSHM-CT-2006-036534), and a cooperative agreement with the National Institute of Neurological Disorders and Stroke (1 U01 NS 40069-01 A2). cells, the ER is the site of three major physiologic functions: protein folding, intracellular $\mathrm{Ca}^{2+}$ storage, and synthesis of unsaturated fatty acids, sterols, and phospholipids (10). Under various pathologic conditions, the perturbation of any of the three physiologic functions of the ER results in so-called ER stress and can lead to an accumulation of the newly synthesized unfolded and misfolded proteins in the ER. Among the stimuli that promote ER stress are ischemia, inflammation, and disorders that impair the ability of ER to properly fold polypeptides or eliminate unfolded proteins (11).

The ER responds to the presence of misfolded proteins in two ways that influence one another. In the first, called the unfolded protein response (UPR) and a focus of this article, homeostasis is achieved by reducing protein synthesis, restoring the protein-folding capacity of the ER, and clearing away the debris (11). The second, called ER-associated degradation (ERAD), also known as the misfolded protein response (12), specifically recognizes terminally misfolded proteins and moves them across the ER membrane into the cytosol, where they can be degraded (13).

These two systems are intimately linked: UPR induction increases ERAD capacity, loss of ERAD induces UPR, and simultaneous impairments of ERAD and the UPR greatly decrease cell viability.

\section{PATHWAYS AND THE FIGURE}

The next 18 sections deal with pathways identified in the figure, which illustrates the interrelationships between inflammation and ER stress, the central topic of this article. The figure remotely overlaps with, and expands upon, an illustra-

\footnotetext{
Abbreviations: ATF6, activating transcription factor 6; Bax, BCL-2 associated X protein; Bak, BCL2 homologous antagonist/killer; BCL-2, B-cell lymphoma-2; BiP, immunoglobulin heavy chain binding protein; CHOP, C/EBP-homologous protein; CREBH, cAMP-responsive element binding protein H; CRP, c-reactive protein; ER, endoplasmic reticulum; ERAD, ER-associated degradation; IRE1, inositol requiring 1; KA, kainic acid; OLs, oligodendrocytes; pre-OLs, premyelinating oligodendrocytes; PERK, PKRlike ER kinase; ROS, reactive oxygen species; UPR, unfolded protein response
} 


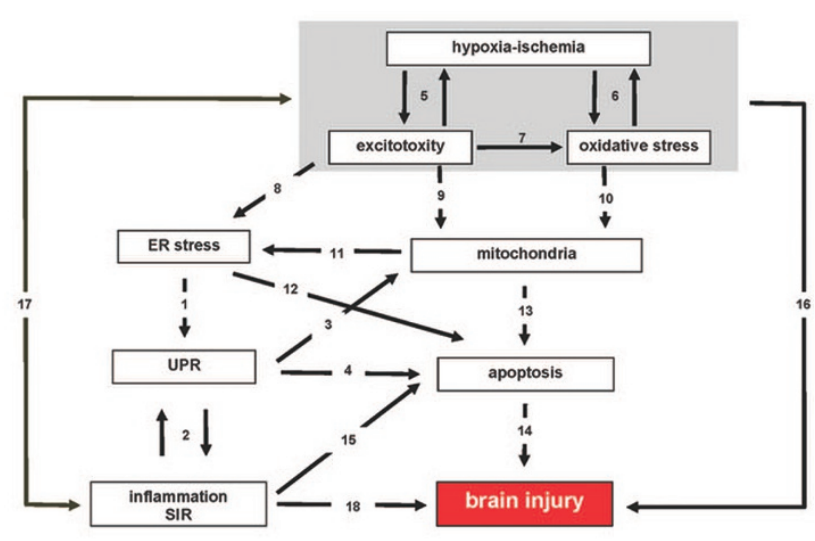

Figure 1. Interrelationships between endoplasmic reticulum stress, inflammation, and perinatal brain damage.

tion from an article that focused on a role for mitochondria in damage to the immature brain (14).

\section{Pathway 1: ER Stress $\rightarrow$ UPR}

Events like disorders or insults can activate the UPR signal transduction pathways.

The UPR has at least three main pathways, each named for a membrane-anchored protein whose cytoplasmic domain is released from the ER when it is stressed:

1) the PERK/eIF2 $\alpha$ [PKR-like ER kinase (PERK)/eukaryotic initiation factor (eIF) 2alpha] pathway applies an "emergency brake" to prevent further synthesis of proteins. PERK induces phosphorylation of eIF2 $\alpha$, resulting in shutdown of translation at the initiation step. This stops the synthesis of proteins that cannot be correctly folded in the ER and thus protects cells from the effect of additional unfolded proteins.

2) the ATF6 (activating transcription factor 6) pathway augments ER protein folding capacity. ATF6 is a key transcription factor in the resolution of the mammalian UPR and is made initially as ER-resident transmembrane protein. ATF6 is a $90 \mathrm{kD}$ basic leucine zipper protein that binds to the ER stress response element and enhances transcription of genes encoding glucose-regulated proteins (GRP). In response to ER stress, endogenous ATF6 is cleaved by a process termed regulated intramembrane proteolysis to a transcriptionally competent $50 \mathrm{kD}$ protein, which allows it to translocate from the ER to the Golgi apparatus.

Activation of the ATF6 limb of the UPR may exert protective effects in experimental ischemic injury through expression of proteins (including $\mathrm{Ca}^{2+}$-dependent molecular chaperones GRP78 and GRP94) (15). These proteins, strategically poised within the ER, can orchestrate the stabilization of protein intermediates, prevent protein misfolding, and up-regulate functions downstream that enhance quality control mechanisms and compartment-specific cellular adaption (16).

3) IRE1 (inositol requiring 1) not only detects misfolded ER proteins but also increases folding capacity by two mech- anisms. One activates a transcription factor, X-box-binding protein 1 (XBP-1), which increases the expression of the chaperone GRP78 (17). The other promotes the degradation of specific mRNAs (18).

Professional secretory cells of endocrine and exocrine organs are well equipped to synthesize large amounts of protein. Nevertheless, a general axiom is that the higher the protein synthesis rate, the higher the probability of ER stress.

In the adult, OLs synthesize $\sim 100,000$ myelin-specific proteins per minute (19). Mature OLs are very sensitive to ER stress $(20,21)$. The protein synthesis demands made on immature OLs or their precursors are currently unknown. We raise the possibility that the neonatal brain is especially vulnerable to ER stress because of the abundant protein synthesis by preoligodendrocytes and maturing OLs.

Efficient folding of many newly synthesized proteins depends on assistance from molecular chaperones, which serve to prevent protein misfolding and aggregation in the crowded environment of the cell. Nascent chain-binding chaperones, including trigger factor, Hsp70, and prefoldin, stabilize elongating chains on ribosomes in a nonaggregated state. Folding in the cytosol is achieved by these chaperones or after transfer of newly synthesized proteins to downstream chaperones, such as the chaperonins (22).

It is still unclear how the ER recognizes misfolded proteins. Current evidence suggests that all three major membraneanchored proteins (PERK, ATF6, and IRE1) function as sensors of stress. The existence of multiple UPR sensors in higher eukaryotes allows for a more nuanced response to misfolded proteins.

New studies suggest a model by which distinct combinations of individual UPR signaling pathways determine a cell's fate after ER stress. The switch between cytoprotective and also proapoptotic output seems to lie in part in the duration of individual UPR branch activity (23). The initial combined activation of IRE1, PERK, and ATF6 produces cytoprotective outputs such as reduced translation, enhanced ER protein folding capacity, and clearance of misfolded ER proteins, along with proapoptotic outputs such as CHOP (C/EBP homologous protein) production (23). Cytoprotective outputs would outweigh proapoptotic factors at this point, which would be helped by the relatively longer mRNA and protein half lives of factors such as immunoglobulin heavy chain binding protein (BiP) (24). This phase of predominantly beneficial UPR output would thus provide a "window of opportunity" for cells to readjust their ER to cope with stress. If these steps fail to reestablish homeostasis, IRE1 and ATF6 signaling are attenuated, creating an imbalance in which unchecked proapoptotic output guides the cell toward its demise (23).

Low-level activation of the UPR is accompanied by changes in the patterns of protein expressions that are qualitatively distinct from the UPR induced by severe acute stress (24). Adaptation to chronic stress is a consequence not of selective activation of proximal ER stress sensors but of preferential stabilization of mRNAs and proteins that facilitate adaptation. 


\section{Pathway 2: UPR $\leftrightarrow$ Inflammation/Systemic Inflammatory Response (SIR)}

Inflammation is a major component of perinatal damage to the lung (25) and brain (1,26) and might be a common final pathway in both (8). In the following sections, we discuss the bidirectional links between inflammation and the UPR.

Inflammation $\rightarrow \boldsymbol{U P R}$. TNF-alpha can induce the UPR (27), which, in turn, is able to attenuate IL-1 (IL-1) and IFN-gamma signaling (at least in pancreatic beta cells) (28).

Lipopolysaccharide can have numerous, sometimes opposite, effects on the ER. First, it can increase the expression level of chaperones in the ER lumen (29). This should be expected to decrease ER stress. Second, it can cause ER stress as documented by the activation of PERK, one of the proteins in the UPR, and even ER disintegration (30). In mice, systemic lipopolysaccharide activates lung CHOP, another gene involved in the UPR (31). Third, it can prevent ER stress and resulting apoptosis induced by some toxins (32).

$\boldsymbol{U P R} \rightarrow$ Inflammation. CHOP, as well as the three proteins with pathway names (PERK, ATF6, IRE1) are not the only ones that mediate the UPR. CREBH (cAMP-responsive element binding protein $\mathrm{H}$ ), a new member of the membrane bound transcription factor family that is structurally similar to ATF6, is liver specific and can be detected as early as mid-gestation (33). After being cleaved in response to ER stress, the active component transits to the nucleus, where it activates expression of acute phase response genes, such as those encoding c-reactive protein (CRP).

Observations that noninflammatory phenomena contribute to ER stress have led to the "intriguing notion that many physiologic and pathologic processes that induce ER stress ... can induce an inflammatory response through CREBH cleavage and CRP production" (33). The expression of CREBH is induced by proinflammatory cytokines, and ER stress induces cleavage of CREBH. The CREBH does not contribute to the classical UPR induction, but it is required for the acute phase response by regulating transcription of CRP and other acute phase reactants. CREBH and ATF6 bind to a conserved promoter element in the specific acute phase response genes where they interact and synergistically activate transcription of target genes upon ER stress (33). Knowing that proinflammatory cytokines induce cleavage of CREBH and activate the acute phase response and the UPR in the liver in vivo, we consider the following sequence and inference:

- Noninflammatory stimuli can lead to ER stress and the UPR.

- CREBH, a member of the ATF6 family of ER membranebound transcription factors and activated by the UPR, also contributes to the UPR in the liver, which, in turn, promotes CRP synthesis.

- CRP promotes systemic inflammation (34).

- Systemic inflammation contributes to perinatal brain damage, particularly the white matter (1,35-37).

- Consequently, the noninflammatory stimuli that lead to ER stress induce cleavage of CREBH, which, in turn, promotes CRP synthesis leading to systemic inflammation that can contribute to perinatal white matter damage.

\section{Pathway 3: UPR $\rightarrow$ Mitochondria}

Under conditions of prolonged ER stress, the UPR, unable to maintain ER homeostasis, triggers apoptosis. Multiple pathways may be involved in ER-stress mediated apoptosis, including direct activation of caspases in the ER, transcriptional activation of the apoptotic program through the modulation of BCL-2 (B-cell lymphoma-2) members or death receptors, and the mitochondrial pathway involving the up-regulation of the proapoptotic and down-regulation of the antiapoptotic BCL-2 members of proteins $(38,39)$. These apoptotic responses are activated via the important $\mathrm{Ca}^{2+}$-mediated "ER-mitochondrial crosstalk" (39), which is facilitated/regulated by mitochondria $(40,41)$. The BCL-2 proteins are important regulators of apoptosis at both the ER, and the mitochondria, and may have similar functions in both organelles (38).

\section{Pathway 4: UPR $\rightarrow$ Apoptosis}

The complex UPR is a prosurvival, cytoprotective response to reduce the accumulation of unfolded and misfolded proteins, and to restore the ER to its normal state. However, when a stressor is so strong or persistent that ER function cannot be restored, apoptosis occurs, leading to targeted removal of cells that are irreparably damaged (42). Given the central role of the three ER transmembrane receptors (Pathway 1) in UPR signaling, it is likely that these mediators are also fundamental to ER stress-induced apoptosis $(43,44)$. Activation of PERK is initially protective. However, the activation of PERK also leads to the induction of CHOP, an important element of the switch from prosurvival to prodeath signaling (44). Although ATF6 can induce CHOP mRNA expression, it seems that ATF6-mediated signals are purely prosurvival (11), whereas IRE1 reveals both pro- and antiapoptotic functions (44). Although these crucial mediators can trigger proapoptotic signals, they do not directly cause cell death but rather initiate downstream molecules such as CHOP, JNK, or BCL-2, which further push the cell down the path of death. Interestingly, recent data suggest that Bax inhibitor-1 (BI-1), an ER resident protein interacting with the proapoptotic protein BCL-2 associated X protein (Bax) and known to neutralize Bax's proapoptotic activity, can inhibit the IRE1 $\alpha$-dependent branch of the UPR (45). The fact that the UPR is suppressed by BI-1 under stress conditions seems to contradict its welldocumented antiapoptotic activity (45).

\section{Pathway 5: Hypoxia-Ischemia $\leftrightarrow$ Excitotoxicity}

Hypoxia-ischemia, a purported mechanism of perinatal brain damage (14), results in depletion of cellular energy stores, depolarization of neurons and glia, and the release of excitatory amino acids into the extracellular space. Energydependent reuptake mechanisms become compromised allowing glutamate to accumulate to excitotoxic levels (46-48). Glutamate is capable of inducing maturation-dependent death of premyelinating oligodendrocytes (pre-OLs). The loss of pre-OLs characterizes the cerebral white matter injury, which is the most common form of injury to the preterm brain and is associated with high risk of neurodevelopmental impairment 
(49). Excitotoxic cell death can also occur in all neurons possessing glutamate receptors as well as in glial cells including astrocytes and OLs. OLs seem to be highly vulnerable to excitotoxic overactivation and a physiologic functioning of glutamate homeostasis seems to be crucial to prevent glutamate-induced damage to OLs (50).

\section{Pathway 6: Hypoxia-Ischemia $\leftrightarrow$ Oxidative Stress}

In the developing brain, hypoxia increases anaerobic metabolism, leading to a rapid rise in levels of lactic acid and reactive oxygen species (ROS) production (51), and/or impaired function of the antioxidant defense mechanism $(52,53)$. Preterm newborns are at high risk of oxidative stress and are very susceptible to free radical oxidative damage (54). In the very immature brain, oxidative stress is an important factor in the response of the immature brain to hypoxic-ischemic injury (55). Additionally, oligodendrocyte progenitor cells and oligodendrocyte precursors are selectively vulnerable to the depletion of antioxidants or exposure to free radicals (56).

\section{Pathway 7: Excitotoxicity $\rightarrow$ Oxidative Stress}

The pattern of brain oxidative injury is dependent on the developmental stage of the brain. Increased release of glutamate and glutamate action has been implicated in rodent studies of preterm white matter injury $(3,57,58)$. Glutamateinduced injury to pre-OLs is mediated by ionotropic glutamate receptors (iGluRs) of the AMPA/kainate type (59-62). Activation of mGluRs attenuates oligodendrocyte excitotoxicity by controlling downstream oxidative stress after iGluR overactivation (57). Excessive extracellular glutamate causes glutathione depletion in pre-OLs with consequent free radical generation (63). Reactive oxygen and nitrogen species are found in damaged white matter of human newborns (64).

\section{Pathway 8: Excitotoxicity $\rightarrow$ ER Stress}

Perinatal insults can disrupt synaptic function leading to accumulation of extracellular glutamate and excessive stimulation of the several groups of glutamate receptors [NMDA, AMPA, kainate, and metabotropic receptors (mGluRs)]. Activation of NMDA receptors does not seem to significantly modulate ER stress signaling pathways (65). On the other hand, another excitatory transmitter, kainic acid (KA), activates ER sensors that are part of the PERK, ATF6, and IRE1 pathways (66). The mode of cell death caused by KA includes the activation of caspases as well as changes in expression of various pro- and antiapoptotic molecules (67). KA induces fragmentation of the ER membrane in neurons, which in turn activates the ER proteins Bip and CHOP.

Although controversial, one view is that the resulting cleavage of caspase-12 is the death-driving force in ER stress $(66,68)$. The apoptosome, a large ternary protein structure formed in the process of apoptosis, acts upstream of caspase-12 cleavage resulting in cell death that does not require caspase-12 activity $(69,70)$. The execution of cell death prompted by ER stress can also be achieved via other caspases, e.g., caspase-2 (71), caspase-3 (72), or caspase-9 (73).

\section{Pathway 9: Excitotoxicity $\rightarrow$ Mitochondria}

Glutamate, a major excitatory neurotransmitter in the brain, can cause excitotoxic injury to the nervous system under many pathologic circumstances. Emerging evidence indicates that OLs share with neurons a high vulnerability to excitotoxic injury (74-76). Developing OLs (pre-OLs) seem to be more sensitive to excitotoxic death than mature OLs $(3,74-76)$, and pre-OL excitotoxicity is implicated in the pathogenesis of periventricular leukomalacia (PVL), a leading cause of cerebral palsy in premature infants $(2,3,57,74)$. Additionally, the glutamate-receptor agonist KA triggers a delayed type of excitotoxic cell death in vulnerable brain regions $(67,77,78)$ that results in an ER stress response with the activation of the PERK, ATF6, and IRE1 pathways (66).

\section{Pathway 10: Oxidative Stress $\rightarrow$ Mitochondria}

The formation of ROS might be part of early events leading to mitochondrial impairment, excitotoxicity, and apoptosis (14). Immature brains are much more likely than adults to release proapoptotic proteins from mitochondria in response to oxidative stress (14).

\section{Pathway 11: Mitochondria $\rightarrow$ ER Stress}

Increasing evidence supports the view that mitochondria are involved in the apoptosis that follows unresolved ER stress $(48,79-81)$. Some of the apoptosis is due to the release of cytochrome $c$ from the mitochondria, which is regulated by the BCL-2 family of proteins, including Bak (BCL2 homologous antagonist/killer) and Bax $(39,79)$. Although the mitochondrion remains the principle subcellular target of the BCL-2 protein family, the recent finding that certain members of the BCL-2 family are present on the ER where they seem to have a much broader and comprehensive function could lead to the speculation that activities of the proteins at the ER might be more relevant to sustaining cellular function and possibly setting the threshold of sensitivity to apoptotic stimuli (39). Although it is generally accepted that mitochondrial expression of these proteins suffices for apoptosis, it was only discovered very recently that exclusive reticular expression of Bak is sufficient to fully trigger mitochondrial apoptosis (79). These findings support the involvement of an ER to mitochondria apoptotic pathway and reveal that, by not relying on mitochondrial Bak and Bax, ER-localized multidomain effectors might function as autonomous integration sites for apoptotic signals, thus adding a new layer of complexity to the regulation of apoptosis (79).

\section{Pathway 12: ER Stress $\rightarrow$ Apoptosis}

The efficient functioning of the ER is essential for most cellular activities and survival. The accumulation of unfolded proteins in the ER represents a cellular stress induced by multiple stimuli and pathologic conditions. If the ER stress is persistent and the UPR cannot suppress the ER stress, signaling switches from prosurvival to proapoptotic. A number of pathways are involved in ER-stress induced apoptosis, including direct activation of initiator caspases at the ER, transcrip- 
tional activation of the apoptotic program through the modulation of BCL-2 family members or death receptors, and apoptosis through ER-mitochondrial crosstalk. Increasing evidence of an essential role for the three functional groups of proteins comprising the BCL-2 family members at the ER is becoming apparent $(38,45,82,83)$. BCL-2 family proteins at the ER regulate both direct modulation of signaling pathways leading to caspase activation and through the modulation of ER-mitochondria $\mathrm{Ca}^{2+}$ crosstalk signaling (84). Additionally, the BCL-2 family seems to play essential roles in ER apoptosis and in the regulation of autophagy, a degradative survival that limits metabolic stress, genomic instability, and tumorigenesis (38).

\section{Pathway 13: Mitochondria $\rightarrow$ Apoptosis}

Two major pathways of apoptosis have been recognized as the "intrinsic" mitochondrial pathway and the "extrinsic" death receptor pathway. At the core of the mitochondrial pathway is the process of mitochondrial outer membrane permeabilization (MOMP) mediated predominantly by the proapoptotic BCL-2 family members, Bax and Bak, and inhibited by the antiapoptotic BCL-2 family proteins (85). The release of cytochrome $c$ from the mitochondrial membrane space triggers the activation apoptosis protease-activating factor 1 (APAF-1) within the apoptosome, the large protein structure formed in the process of apoptosis, leading to a cascade of caspases that achieve apoptosis by cleaving key substrates (86). Caspase-independent pathways can also involve proapoptotic proteins such as apoptosis inducing factor (AIF), endonucleases G, and BNIP3 $(87,88)$.

By contrast, the extrinsic cell death pathway can function independently of mitochondria and is activated by cell-surface receptors. These cell surface death receptors belong to the tumor necrosis factor receptor (TNFR) superfamily and include TNF-R1, Fas (also called CD95), death receptor 3 (DR3), and two tumor necrosis factor-related apoptosisinducing ligand (TRAIL) receptors (89). A shared feature of death receptors is the death domain in the cytoplasmic tail of these molecules. Ligand binding to the death domain leads to the creation of a death-inducing signaling complex (DISC) directly activating the caspase cascade via an initiator caspase (caspase-8) resulting in the cleavage of caspase-3 in the execution phase of apoptosis (90).

\section{Pathway 14: Apoptosis $\rightarrow$ Brain Injury}

Apoptosis, needed for eliminating nonfunctional cells during normal brain development with a minimum of inflammation, plays a prominent role in neonatal brain injury (91-93). Immature neurons seem to be more prone to apoptotic death than terminally differentiated neurons (94). Additionally, signals from TNF/Fas receptors result in apoptosis when endogenous inhibitors of apoptosis are deficient. Fas-dependent signaling pathways can contribute to apoptosis in the immature brain in response to hypoxia-ischemia $(95,96)$ and head trauma $(97,98)$. In addition, Fas and its ligand FasL have been detected in neonatal cerebrospinal fluid $(99,100)$.

\section{Pathway 15: Inflammation $\rightarrow$ Apoptosis}

The up-regulation of proinflammatory cytokines (e.g., TNF- $\alpha$, interferon-gamma, IL-1, IL-6, and IL-10) in response to a strong proinflammatory challenge can lead to deleterious effects in the developing brain (101). TNF- $\alpha$ receptors have been identified in human brains with PVL, raising the possibility that activation of these TNF- $\alpha$ receptors contributes to inflammatory reactions and apoptosis (102). Indeed, apoptosis is prominent in the brains of infants who died with white matter injury (103). Exposing developing OLs to TNF increases apoptosis (104) and reduces staining for myelin basic protein (MBP) (105), which might help explain the reduced myelination that is considered a hallmark of inflammationassociated white matter damage in preterm infants (106).

Additional essential regulators of inflammation are enzymes termed "the inflammatory caspases." They are activated by cellular sensors of danger signals, the inflammasomes, and subsequently convert proinflammatory cytokines into their mature active forms (107). By acting as key regulators of inflammation, energy metabolism, and cell death, inflammatory caspases and inflammasomes exert profound influences on innate immunity and infectious and noninfectious inflammatory diseases (107).

\section{Pathway 16: Hypoxia-Ischemia $\rightarrow$ Brain Damage}

Hypoxia-ischemia has been the experimental paradigm for perinatal brain damage over the past decades. The reader is referred to Hagberg et al. (108) for a comprehensive overview.

\section{Pathway 17: Hypoxia-Ischemia $\leftrightarrow$ Inflammation/SIR}

The relationships between hypoxia-ischemia and inflammation are highly complex. Hypoxia-ischemia and inflammation each alone (109), as well as together (preconditioning or sensitizing) (110,111), can contribute to brain damage. Preconditioning, also known as tolerance, constitutes the phenomenon where exposure to a sublethal insult, before a severe insult, attenuates the pathology. Protective in a number of organs and in both adult and immature animals, preconditioning has also followed many different kinds of sublethal insults, including hypoxia, ischemia, inflammatory cytokines, and endotoxins (110). It is not necessary for the sublethal event to be the same type as the secondary insult (so-called crosstolerance). The underlying mechanisms of preconditioning remain largely unknown.

Sensitization, also known as negative preconditioning, occurs when a sublethal insult exacerbates the damage of a subsequent severe insult. Because both inflammation and hypoxia-ischemia have the ability to contribute to ER stress and therefore to activate the UPR pathways, these propensities might be linked.

\section{Pathway 18: Inflammation $\rightarrow$ Brain Injury}

Preterm infants exposed to chorioamnionitis (36), fetal vasculitis (35), high concentrations of proinflammatory cytokines in the amniotic fluid (37), or fetal blood (112) are at increased risk of white matter injury and/or cerebral palsy 
(CP). Intracerebral and systemic lipopolysaccharide injections induce inflammatory responses and prominent white matter lesions [for an overview see (26)]. Taken together, the evidence from both observational and experimental research suggests that the association between inflammation and brain injury is causal (1).

\section{CLINICAL EXAMPLES}

Endoplasmic stress and the UPR have been implicated in a number of neurologic disorders, including Alzheimer's disease (113), amyotrophic lateral sclerosis (114) in adults, the leukodystrophy Pelizaeus-Merzbacher disease (115), and the vanishing white matter disease (116) in children.

Vanishing white matter disease is one of the most prevalent autosomal-recessive childhood leucoencephalopathies in which febrile infections or minor head trauma may provoke major neurologic deterioration leading to cerebellar ataxia and spasticitiy. All three main UPR pathways mentioned in pathway 1 are activated in patients with vanishing white matter disease (117). The activation seems to be restricted to the white matter and enhanced expression of UPR markers (e.g., ATF6, BiP) is almost exclusively observed in the OLs and astrocytes. These cells are known to be primarily involved in the pathology of vanishing white matter disease (117).

Pelizaeus-Merzbacher leucodystrophy is a neurodegenerative disease causing diffuse hypomyelination of the CNS. The severity and onset of this X-linked recessive pediatric disorder ranges widely and extends from the mild, adult-onset spastic paraplegia to the severe form with onset at infancy and death in early childhood. One possible pathogenic mechanism could be the UPR activation and signaling through the UPR downstream effector molecule CHOP (118). This CHOP protein, widely known as a proapoptotic transcription factor, modulates the pathogenesis in different mouse models of PelizaeusMerzbacher disease, indicating that this protein might be a key regulatory component (118).

We extend the possibility of UPR-induced apoptosis to the brain of the most vulnerable humans, those born much before term. OLs produce a vast amount of myelin as an extension of their plasma membranes (119). If the immature OLs that characterize the cerebral white matter near the end of the second trimester synthesize proteins, they might be prone to ER stress during their active phase and thereby highly vulnerable to apoptosis via UPR failure leading to brain injury. Thus, it could be that the outcome of ER stress is determined by the developmental status of the cell.

\section{CONCLUSION}

Although infection can lead to a fetal inflammatory response, noninflammatory stimuli can initiate/promote inflammatory phenomena via ER stress leading to the UPR, which might then lead to brain damage. Although recent advances in our understanding of intracellular stress responses add yet another level of complexity to this evolving story, they might also open new avenues for interventions (43). On the one hand, ER stress promotes cell survival in fully myelinated mature OLs (120). On the other hand, ER stress leads actively myelinating/remyelinating OLs to cell death (121). How the UPR in response to ER stress selectively promotes apoptotic and adaptive pathways remains unknown (42). Perhaps the fate of the (pre-) oligodendrocyte depends on the developmental status of the cell or the amount of protein production. The neonatal brain might be especially vulnerable to ER stress because of the abundant protein synthesis by preoligodendrocytes and myelinating OLs. Perhaps acute interventions to limit the UPR can minimize this neonatal brain damage (43). Among the challenges posed by interfering with the UPR are how best to achieve this goal in light of the multiple pathways involved in the apoptosis that follows unresolved UPR and minimizing unintended disturbances to processes needed for normal development (120). Continued research in this exciting field is needed to improve our understanding of how these pathways are linked and how brain damage that follows activation of these pathways might be minimized.

\section{REFERENCES}

1. Dammann O, Leviton A 2004 Inflammatory brain damage in preterm newbornsdry numbers, wet lab, and causal inferences. Early Hum Dev 79:1-15

2. Follett PL, Deng W, Dai W, Talos DM, Massillon LJ, Rosenberg PA, Volpe JJ, Jensen FE 2004 Glutamate receptor-mediated oligodendrocyte toxicity in periventricular leukomalacia: a protective role for topiramate. J Neurosci 24:4412-4420

3. Follett PL, Rosenberg PA, Volpe JJ, Jensen FE 2000 NBQX attenuates excitotoxic injury in developing white matter. J Neurosci 20:9235-9241

4. Volpe JJ 2001 Perinatal brain injury: from pathogenesis to neuroprotection. Ment Retard Dev Disabil Res Rev 7:56-64

5. Dommergues MA, Plaisant F, Verney C, Gressens P 2003 Early microglial activation following neonatal excitotoxic brain damage in mice: a potential target for neuroprotection. Neuroscience 121:619-628

6. Mesples B, Plaisant F, Fontaine RH, Gressens P 2005 Pathophysiology of neonatal brain lesions: lessons from animal models of excitotoxicity. Acta Paediatr 94:185-190

7. Tahraoui SL, Marret S, Bodenant C, Leroux P, Dommergues MA, Evrard P, Gressens P 2001 Central role of microglia in neonatal excitotoxic lesions of the murine periventricular white matter. Brain Pathol 11:56-71

8. Dammann O, Leviton A, Gappa M, Dammann CE 2005 Lung and brain damage in preterm newborns, and their association with gestational age, prematurity subgroup, infection/inflammation and long term outcome. BJOG 112:4-9

9. Dammann O, Leviton A 1997 Maternal intrauterine infection, cytokines, and brain damage in the preterm newborn. Pediatr Res 42:1-8

10. Schroder M 2008 Endoplasmic reticulum stress responses. Cell Mol Life Sci 65:862-894

11. Schroder M, Kaufman RJ 2005 The mammalian unfolded protein response. Annu Rev Biochem 74:739-789

12. Meusser B, Hirsch C, Jarosch E, Sommer T 2005 ERAD: the long road to destruction. Nat Cell Biol 7:766-772

13. Romisch K 2005 Endoplasmic reticulum-associated degradation. Annu Rev Cell Dev Biol 21:435-456

14. Blomgren K, Hagberg H 2006 Free radicals, mitochondria, and hypoxia-ischemia in the developing brain. Free Radic Biol Med 40:388-397

15. Martindale JJ, Fernandez R, Thuerauf D, Whittaker R, Gude N, Sussman MA, Glembotski CC 2006 Endoplasmic reticulum stress gene induction and protection from ischemia/reperfusion injury in the hearts of transgenic mice with a tamoxifenregulated form of ATF6. Circ Res 98:1186-1193

16. Xu C, Bailly-Maitre B, Reed JC 2005 Endoplasmic reticulum stress: cell life and death decisions. J Clin Invest 115:2656-2664

17. Credle JJ, Finer-Moore JS, Papa FR, Stroud RM, Walter P 2005 On the mechanism of sensing unfolded protein in the endoplasmic reticulum. Proc Natl Acad Sci USA 102:18773-18784

18. Hollien J, Weissman JS 2006 Decay of endoplasmic reticulum-localized mRNAs during the unfolded protein response. Science 313:104-107

19. Southwood C, Gow A 2001 Molecular pathways of oligodendrocyte apoptosis revealed by mutations in the proteolipid protein gene. Microsc Res Tech 52:700-708

20. Lin W, Harding HP, Ron D, Popko B 2005 Endoplasmic reticulum stress modulates the response of myelinating oligodendrocytes to the immune cytokine interferongamma. J Cell Biol 169:603-612

21. Goldbaum O, Richter-Landsberg C 2002 Activation of PP2A-like phosphatase and modulation of tau phosphorylation accompany stress-induced apoptosis in cultured oligodendrocytes. Glia 40:271-282

22. Hartl FU, Hayer-Hartl M 2002 Molecular chaperones in the cytosol: from nascent chain to folded protein. Science 295:1852-1858 
23. Lin JH, Li H, Yasumura D, Cohen HR, Zhang C, Panning B, Shokat KM, Lavail MM, Walter P 2007 IRE1 signaling affects cell fate during the unfolded protein response. Science 318:944-949

24. Rutkowski DT, Arnold SM, Miller CN, Wu J, Li J, Gunnison KM, Mori K, Sadighi Akha AA, Raden D, Kaufman RJ 2006 Adaptation to ER stress is mediated by differential stabilities of pro-survival and pro-apoptotic mRNAs and proteins. PLoS Biol 4:e374

25. Speer CP 2006 Inflammation and bronchopulmonary dysplasia: a continuing story. Semin Fetal Neonatal Med 11:354-362

26. Wang X, Rousset CI, Hagberg H, Mallard C 2006 Lipopolysaccharide-induced inflammation and perinatal brain injury. Semin Fetal Neonatal Med 11:343-353

27. Xue X, Piao JH, Nakajima A, Sakon-Komazawa S, Kojima Y, Mori K, Yagita H, Okumura K, Harding H, Nakano H 2005 Tumor necrosis factor alpha (TNFalpha) induces the unfolded protein response (UPR) in a reactive oxygen species (ROS)dependent fashion, and the UPR counteracts ROS accumulation by TNFalpha. J Biol Chem 280:33917-33925

28. Weber SM, Chambers KT, Bensch KG, Scarim AL, Corbett JA 2004 PPARgamma ligands induce ER stress in pancreatic beta-cells: ER stress activation results in attenuation of cytokine signaling. Am J Physiol Endocrinol Metab 287:E1171E1177

29. Lewis MJ, Mazzarella RA, Green M 1985 Structure and assembly of the endoplasmic reticulum. The synthesis of three major endoplasmic reticulum proteins during lipopolysaccharide-induced differentiation of murine lymphocytes. J Biol Chem 260:3050-3057

30. Schildberg FA, Schulz S, Dombrowski F, Minor T 2005 Cyclic AMP alleviates endoplasmic stress and programmed cell death induced by lipopolysaccharides in human endothelial cells. Cell Tissue Res 320:91-98

31. Endo M, Oyadomari S, Suga M, Mori M, Gotoh T 2005 The ER stress pathway involving CHOP is activated in the lungs of LPS-treated mice. J Biochem 138:501-507

32. Islam S, Hassan F, Tumurkhuu G, Ito H, Koide N, Mori I, Yoshida T, Yokochi T 2006 Lipopolysaccharide prevents apoptosis induced by brefeldin A, an endoplasmic reticulum stress agent, in RAW 264.7 cells. Biochem Biophys Res Commun 340:589-596

33. Zhang K, Shen X, Wu J, Sakaki K, Saunders T, Rutkowski DT, Back SH, Kaufman RJ 2006 Endoplasmic reticulum stress activates cleavage of CREBH to induce a systemic inflammatory response. Cell 124:587-599

34. Gabay C, Kushner I 1999 Acute-phase proteins and other systemic responses to inflammation. N Engl J Med 340:448-454

35. Leviton A, Paneth N, Reuss ML, Susser M, Allred EN, Dammann O, Kuban K, Van Marter LJ, Pagano M, Hegyi T, Hiatt M, Sanocka U, Shahrivar F, Abiri M, DiSalvo D, Doubilet P, Kairam R, Kazam E, Kirpekar M, Rosenfeld D, Schonfeld S, Share J, Collins M, Genest D, Heller D, Shen-Schwarz S 1999 Maternal infection, fetal inflammatory response, and brain damage in very low birthweight infants. Pediatr Res 46:566-575

36. Wu YW 2002 Systematic review of chorioamnionitis and cerebral palsy. Ment Retard Dev Disabil Res Rev 8:25-29

37. Yoon BH, Romero R, Park JS, Kim CJ, Kim SH, Choi JH, Han TR 2000 Fetal exposure to an intra-amniotic inflammation and the development of cerebral palsy at the age of three years. Am J Obstet Gynecol 182:675-681

38. Heath-Engel HM, Chang NC, Shore GC 2008 The endoplasmic reticulum in apoptosis and autophagy: role of the BCL-2 protein family. Oncogene 27:64196433

39. Szegezdi E, Macdonald DC, Ni Chonghaile T, Gupta S, Samali A 2009 Bcl-2 family on guard at the ER. Am J Physiol Cell Physiol 296:C941-C953

40. Pizzo P, Pozzan T 2007 Mitochondria-endoplasmic reticulum choreography: structure and signaling dynamics. Trends Cell Biol 17:511-517

41. Rasheva VI, Domingos PM 2009 Cellular responses to endoplasmic reticulum stress and apoptosis. Apoptosis 14:996-1007

42. Boyce M, Yuan J 2006 Cellular response to endoplasmic reticulum stress: a matter of life or death. Cell Death Differ 13:363-373

43. Kim I, Xu W, Reed JC 2008 Cell death and endoplasmic reticulum stress: disease relevance and therapeutic opportunities. Nat Rev Drug Discov 7:1013-1030

44. Szegezdi E, Logue SE, Gorman AM, Samali A 2006 Mediators of endoplasmic reticulum stress-induced apoptosis. EMBO Rep 7:880-885

45. Lisbona F, Rojas-Rivera D, Thielen P, Zamorano S, Todd D, Martinon F, Glavic A, Kress C, Lin JH, Walter P, Reed JC, Glimcher LH, Hetz C 2009 BAX inhibitor-1 is a negative regulator of the ER stress sensor IRE1alpha. Mol Cell 33:679-691

46. Manning SM, Talos DM, Zhou C, Selip DB, Park HK, Park CJ, Volpe JJ, Jensen FE 2008 NMDA receptor blockade with memantine attenuates white matter injury in a rat model of periventricular leukomalacia. J Neurosci 28:6670-6678

47. Salter MG, Fern R 2005 NMDA receptors are expressed in developing oligodendrocyte processes and mediate injury. Nature 438:1167-1171

48. Johnston MV 2005 Excitotoxicity in perinatal brain injury. Brain Pathol 15:234240

49. Khwaja O, Volpe JJ 2008 Pathogenesis of cerebral white matter injury of prematurity. Arch Dis Child Fetal Neonatal Ed 93:F153-F161

50. Matute C, Alberdi E, Domercq M, Sanchez-Gomez MV, Perez-Samartin A, Rodriguez-Antiguedad A, Perez-Cerda F 2007 Excitotoxic damage to white matter. J Anat 210:693-702

51. Fridovich I 1998 Oxygen toxicity: a radical explanation. J Exp Biol 201:1203-1209

52. Halliwell B, Cross CE 1994 Oxygen-derived species: their relation to human disease and environmental stress. Environ Health Perspect 102:5-12

53. Sies H 1997 Oxidative stress: oxidants and antioxidants. Exp Physiol 82:291-295

54. Maltepe E, Saugstad OD 2009 Oxygen in health and disease: regulation of oxygen homeostasis-clinical implications. Pediatr Res 65:261-268
55. Fullerton HJ, Ditelberg JS, Chen SF, Sarco DP, Chan PH, Epstein CJ, Ferriero DM 1998 Copper/zinc superoxide dismutase transgenic brain accumulates hydrogen peroxide after perinatal hypoxia ischemia. Ann Neurol 44:357-364

56. Baud O, Greene AE, Li J, Wang H, Volpe JJ, Rosenberg PA 2004 Glutathione peroxidase-catalase cooperativity is required for resistance to hydrogen peroxide by mature rat oligodendrocytes. J Neurosci 24:1531-1540

57. Deng W, Wang H, Rosenberg PA, Volpe JJ, Jensen FE 2004 Role of metabotropic glutamate receptors in oligodendrocyte excitotoxicity and oxidative stress. Proc Natl Acad Sci USA 101:7751-7756

58. Liu HN, Giasson BI, Mushynski WE, Almazan G 2002 AMPA receptor-mediated toxicity in oligodendrocyte progenitors involves free radical generation and activation of JNK, calpain and caspase 3. J Neurochem 82:398-409

59. Borges K, Ohlemeyer C, Trotter J, Kettenmann H 1994 AMPA/kainate receptor activation in murine oligodendrocyte precursor cells leads to activation of a cation conductance, calcium influx and blockade of delayed rectifying $\mathrm{K}+$ channels. Neuroscience 63:135-149

60. Fern R, Moller T 2000 Rapid ischemic cell death in immature oligodendrocytes: a fatal glutamate release feedback loop. J Neurosci 20:34-42

61. Itoh T, Beesley J, Itoh A, Cohen AS, Kavanaugh B, Coulter DA, Grinspan JB, Pleasure D 2002 AMPA glutamate receptor-mediated calcium signaling is transiently enhanced during development of oligodendrocytes. J Neurochem $81: 390-402$

62. Sanchez-Gomez MV, Matute C 1999 AMPA and kainate receptors each mediate excitotoxicity in oligodendroglial cultures. Neurobiol Dis 6:475-485

63. Back SA, Gan X, Li Y, Rosenberg PA, Volpe JJ 1998 Maturation-dependent vulnerability of oligodendrocytes to oxidative stress-induced death caused by glutathione depletion. J Neurosci 18:6241-6253

64. Haynes RL, Folkerth RD, Keefe RJ, Sung I, Swzeda LI, Rosenberg PA, Volpe JJ, Kinney HC 2003 Nitrosative and oxidative injury to premyelinating oligodendrocytes in periventricular leukomalacia. J Neuropathol Exp Neurol 62:441-450

65. Concannon CG, Ward MW, Bonner HP, Kuroki K, Tuffy LP, Bonner CT, Woods I, Engel T, Henshall DC, Prehn JH 2008 NMDA receptor-mediated excitotoxic neuronal apoptosis in vitro and in vivo occurs in an ER stress and PUMA independent manner. J Neurochem 105:891-903

66. Sokka AL, Putkonen N, Mudo G, Pryazhnikov E, Reijonen S, Khiroug L, Belluardo N, Lindholm D, Korhonen L 2007 Endoplasmic reticulum stress inhibition protects against excitotoxic neuronal injury in the rat brain. J Neurosci 27:901-908

67. Sokka AL, Mudo G, Aaltonen J, Belluardo N, Lindholm D, Korhonen L 2005 Bruce/apollon promotes hippocampal neuron survival and is downregulated by kainic acid. Biochem Biophys Res Commun 338:729-735

68. Rao RV, Ellerby HM, Bredesen DE 2004 Coupling endoplasmic reticulum stress to the cell death program. Cell Death Differ 11:372-380

69. Di Sano F, Ferraro E, Tufi R, Achsel T, Piacentini M, Cecconi F 2006 Endoplasmic reticulum stress induces apoptosis by an apoptosome-dependent but caspase 12 independent mechanism. J Biol Chem 281:2693-2700

70. Steele AD, Hetz C, Yi CH, Jackson WS, Borkowski AW, Yuan J, Wollmann RH, Lindquist S 2007 Prion pathogenesis is independent of caspase-12. Prion 1:243247

71. Upton JP, Austgen K, Nishino M, Coakley KM, Hagen A, Han D, Papa FR, Oakes SA 2008 Caspase-2 cleavage of BID is a critical apoptotic signal downstream of endoplasmic reticulum stress. Mol Cell Biol 28:3943-3951

72. Meares GP, Zmijewska AA, Jope RS 2008 HSP105 interacts with GRP78 and GSK3 and promotes ER stress-induced caspase-3 activation. Cell Signal 20:347358

73. Cheung HH, Lynn Kelly N, Liston P, Korneluk RG 2006 Involvement of caspase-2 and caspase-9 in endoplasmic reticulum stress-induced apoptosis: a role for the IAPs. Exp Cell Res 312:2347-2357

74. Deng W, Poretz RD 2003 Oligodendroglia in developmental neurotoxicity. Neurotoxicology 24:161-178

75. Deng W, Rosenberg PA, Volpe JJ, Jensen FE 2003 Calcium-permeable AMPA/ kainate receptors mediate toxicity and preconditioning by oxygen-glucose deprivation in oligodendrocyte precursors. Proc Natl Acad Sci USA 100:6801-6806

76. Rosenberg PA, Dai W, Gan XD, Ali S, Fu J, Back SA, Sanchez RM, Segal MM, Follett PL, Jensen FE, Volpe JJ 2003 Mature myelin basic protein-expressing oligodendrocytes are insensitive to kainate toxicity. J Neurosci Res 71:237-245

77. Korhonen L, Belluardo N, Lindholm D 2001 Regulation of X-chromosome-linked inhibitor of apoptosis protein in kainic acid-induced neuronal death in the rat hippocampus. Mol Cell Neurosci 17:364-372

78. Korhonen L, Belluardo N, Mudo G, Lindholm D 2003 Increase in Bcl-2 phosphorylation and reduced levels of $\mathrm{BH} 3$-only $\mathrm{Bcl}-2$ family proteins in kainic acidmediated neuronal death in the rat brain. Eur J Neurosci 18:1121-1134

79. Klee M, Pallauf K, Alcala S, Fleischer A, Pimentel-Muinos FX 2009 Mitochondrial apoptosis induced by $\mathrm{BH} 3$-only molecules in the exclusive presence of endoplasmic reticular Bak. EMBO J 28:1757-1768

80. Chami M, Oules B, Szabadkai G, Tacine R, Rizzuto R, Paterlini-Brechot P 2008 Role of SERCA1 truncated isoform in the proapoptotic calcium transfer from ER to mitochondria during ER stress. Mol Cell 32:641-651

81. Giorgi C, De Stefani D, Bononi A, Rizzuto R, Pinton P 2009 Structural and functional link between the mitochondrial network and the endoplasmic reticulum Int $\mathrm{J}$ Biochem Cell Biol [Epub ahead of print]

82. Hetz CA 2007 ER stress signaling and the BCL-2 family of proteins: from adaptation to irreversible cellular damage. Antioxid Redox Signal 9:2345-2355

83. Malhotra JD, Kaufman RJ 2007 The endoplasmic reticulum and the unfolded protein response. Semin Cell Dev Biol 18:716-731

84. Rong Y, Distelhorst CW 2008 Bcl-2 protein family members: versatile regulators of calcium signaling in cell survival and apoptosis. Annu Rev Physiol 70:73-91 
85. Spierings D, McStay G, Saleh M, Bender C, Chipuk J, Maurer U, Green DR 2005 Connected to death: the (unexpurgated) mitochondrial pathway of apoptosis. Science 310:66-67

86. Kang MH, Reynolds CP 2009 Bcl-2 inhibitors: targeting mitochondrial apoptotic pathways in cancer therapy. Clin Cancer Res 15:1126-1132

87. Elmore S 2007 Apoptosis: a review of programmed cell death. Toxicol Pathol 35:495-516

88. Modjtahedi N, Giordanetto F, Madeo F, Kroemer G 2006 Apoptosis-inducing factor: vital and lethal. Trends Cell Biol 16:264-272

89. Wajant H 2003 Death receptors. Essays Biochem 39:53-71

90. Broughton BR, Reutens DC, Sobey CG 2009 Apoptotic mechanisms after cerebral ischemia. Stroke 40:e331-e339

91. Blomgren K, Zhu C, Wang X, Karlsson JO, Leverin AL, Bahr BA, Mallard C, Hagberg H 2001 Synergistic activation of caspase-3 by m-calpain after neonatal hypoxia-ischemia: a mechanism of "pathological apoptosis"? J Biol Chem 276:10191-10198

92. Hu BR, Liu CL, Ouyang Y, Blomgren K, Siesjo BK 2000 Involvement of caspase-3 in cell death after hypoxia-ischemia declines during brain maturation. J Cereb Blood Flow Metab 20:1294-1300

93. Zhu C, Wang X, Xu F, Bahr BA, Shibata M, Uchiyama Y, Hagberg H, Blomgren K 2005 The influence of age on apoptotic and other mechanisms of cell death after cerebral hypoxia-ischemia. Cell Death Differ 12:162-176

94. Wang X, Karlsson JO, Zhu C, Bahr BA, Hagberg H, Blomgren K 2001 Caspase-3 activation after neonatal rat cerebral hypoxia-ischemia. Biol Neonate 79:172-179

95. Dzietko M, Boos V, Sifringer M, Polley O, Gerstner B, Genz K, Endesfelder S, Borner C, Jacotot E, Chauvier D, Obladen M, Buhrer C, Felderhoff-Mueser U 2008 A critical role for Fas/CD-95 dependent signaling pathways in the pathogenesis of hyperoxia-induced brain injury. Ann Neurol 64:664-673

96. Graham EM, Sheldon RA, Flock DL, Ferriero DM, Martin LJ, O'Riordan DP, Northington FJ 2004 Neonatal mice lacking functional Fas death receptors are resistant to hypoxic-ischemic brain injury. Neurobiol Dis 17:89-98

97. Felderhoff-Mueser U, Ikonomidou C 2000 Mechanisms of neurodegeneration after paediatric brain injury. Curr Opin Neurol 13:141-145

98. Felderhoff-Mueser U, Sifringer M, Pesditschek S, Kuckuck H, Moysich A, Bittigau P, Ikonomidou C 2002 Pathways leading to apoptotic neurodegeneration following trauma to the developing rat brain. Neurobiol Dis 11:231-245

99. Felderhoff-Mueser U, Buhrer C, Groneck P, Obladen M, Bartmann P, Heep A 2003 Soluble Fas (CD95/Apo-1), soluble Fas ligand, and activated caspase 3 in the cerebrospinal fluid of infants with posthemorrhagic and nonhemorrhagic hydrocephalus. Pediatr Res 54:659-664

100. Sival DA, Felderhoff-Muser U, Schmitz T, Hoving EW, Schaller C, Heep 2008 A neonatal high pressure hydrocephalus is associated with elevation of proinflammatory cytokines IL-18 and IFNgamma in cerebrospinal fluid. Cerebrospinal Fluid Res 5:21

101. Cai Z, Lin S, Pang Y, Rhodes PG 2004 Brain injury induced by intracerebral injection of interleukin-1beta and tumor necrosis factor-alpha in the neonatal rat. Pediatr Res 56:377-384

102. Kadhim H, Khalifa M, Deltenre P, Casimir G, Sebire G 2006 Molecular mechanisms of cell death in periventricular leukomalacia. Neurology 67:293-299
103. Chamnanvanakij S, Margraf LR, Burns D, Perlman JM 2002 Apoptosis and white matter injury in preterm infants. Pediatr Dev Pathol 5:184-189

104. Pang Y, Cai Z, Rhodes PG 2005 Effect of tumor necrosis factor-alpha on developing optic nerve oligodendrocytes in culture. J Neurosci Res 80:226-234

105. Cammer W, Zhang H 1999 Maturation of oligodendrocytes is more sensitive to TNF alpha than is survival of precursors and immature oligodendrocytes. J Neuroimmunol 97:37-42

106. Inder TE, Wells SJ, Mogridge NB, Spencer C, Volpe JJ 2003 Defining the nature of the cerebral abnormalities in the premature infant: a qualitative magnetic resonance imaging study. J Pediatr 143:171-179

107. McIntire CR, Yeretssian G, Saleh M 2009 Inflammasomes in infection and inflammation. Apoptosis 14:522-535

108. Hagberg H, Peebles D, Mallard C 2002 Models of white matter injury: comparison of infectious, hypoxic-ischemic, and excitotoxic insults. Ment Retard Dev Disabil Res Rev 8:30-38

109. Mallard C, Welin AK, Peebles D, Hagberg H, Kjellmer I 2003 White matter injury following systemic endotoxemia or asphyxia in the fetal sheep. Neurochem Res 28:215-223

110. Hagberg H, Dammann O, Mallard C, Leviton A 2004 Preconditioning and the developing brain. Semin Perinatol 28:389-395

111. Mallard C, Hagberg H 2007 Inflammation-induced preconditioning in the immature brain. Semin Fetal Neonatal Med 12:280-286

112. Yoon BH, Romero R, Yang SH, Jun JK, Kim IO, Choi JH, Syn HC 1996 Interleukin-6 concentrations in umbilical cord plasma are elevated in neonates with white matter lesions associated with periventricular leukomalacia. Am J Obstet Gynecol 174:1433-1440

113. Ghribi O 2006 The role of the endoplasmic reticulum in the accumulation of beta-amyloid peptide in Alzheimer's disease. Curr Mol Med 6:119-133

114. Turner BJ, Atkin JD 2006 ER stress and UPR in familial amyotrophic lateral sclerosis. Curr Mol Med 6:79-86

115. Forman MS, Lee VM, Trojanowski JQ 2003 'Unfolding' pathways in neurodegenerative disease. Trends Neurosci 26:407-410

116. van der Knaap MS, Barth PG, Gabreels FJ, Franzoni E, Begeer JH, Stroink H, Rotteveel JJ, Valk J 1997 A new leukoencephalopathy with vanishing white matter. Neurology 48:845-855

117. van Kollenburg B, van Dijk J, Garbern J, Thomas AA, Scheper GC, Powers JM, van der Knaap MS 2006 Glia-specific activation of all pathways of the unfolded protein response in vanishing white matter disease. J Neuropathol Exp Neurol 65:707-715

118. Southwood CM, Garbern J, Jiang W, Gow A 2002 The unfolded protein response modulates disease severity in Pelizaeus-Merzbacher disease. Neuron 36:585-596

119. Pfeiffer SE, Warrington AE, Bansal R 1993 The oligodendrocyte and its many cellular processes. Trends Cell Biol 3:191-197

120. Lin W, Bailey SL, Ho H, Harding HP, Ron D, Miller SD, Popko B 2007 The integrated stress response prevents demyelination by protecting oligodendrocytes against immune-mediated damage. J Clin Invest 117:448-456

121. Lin W, Kemper A, Dupree JL, Harding HP, Ron D, Popko B 2006 Interferongamma inhibits central nervous system remyelination through a process modulated by endoplasmic reticulum stress. Brain 129:1306-1318 